\title{
Microvascular density and hypoxia-inducible factor pathway in pancreatic endocrine tumours: negative correlation of microvascular density and VEGF expression with tumour progression
}

\section{A Couvelard,', D O'Toole ${ }^{2}$, H Turley ${ }^{3}$, R Leek ${ }^{3}$, A Sauvanet ${ }^{4}$, C Degott', P Ruszniewski ${ }^{2}$, J Belghiti ${ }^{4}$, AL Harris ${ }^{3}, K_{\text {Gatter }}{ }^{3}$ and F Pezzella ${ }^{3}$}

'Department of Pathology, Hôpital Beaujon, 100 Boulevard du Général Leclerc, 92110 Clichy, France; ²Department of Gastroenterology, Hôpital Beaujon, 100 Boulevard du Général Leclerc, 92110 Clichy, France; ${ }^{3}$ Cancer Research UK, Tumor Pathology Unit, University of Oxford, John Radcliffe Hospital, Oxford OX3 9DU, UK; ${ }^{4}$ Department of Surgery, Hôpital Beaujon, 100 Boulevard du Général Leclerc, 92110 Clichy, France

Tumour-associated angiogenesis is partly regulated by the hypoxia-inducible factor (HIF) pathway. Endocrine tumours are highly vascularised and the molecular mechanisms of their angiogenesis are not fully delineated. The aim of this study is to evaluate angiogenesis and expression of HIF-related molecules in a series of patients with pancreatic endocrine tumours (PETs). The expression of vascular endothelial growth factor (VEGF), HIF-I $\alpha$, HIF- $2 \alpha$ and carbonic anhydrase 9 (CA9) was examined by immunohistochemistry in 45 patients with PETs and compared to microvascular density (MVD), endothelial proliferation, tumour stage and survival. Microvascular density was very high in PETs and associated with a low endothelial index of proliferation. Microvascular density was significantly higher in benign PETs than in PETs of uncertain prognosis, well-differentiated and poorly differentiated carcinomas (mean values: 535, 436, 252 and 45 vessels $\mathrm{mm}^{-2}$, respectively, $P<0.000$ I). Well-differentiated tumours had high cytoplasmic VEGF and HIF- $\mid \alpha$ expression. Poorly differentiated carcinomas were associated with nuclear HIF- $\mid \alpha$ and membranous CA9 expression. Low MVD $(P=0.0001)$ and membranous CA9 expression $(P=0.0004)$ were associated with a poorer survival. Contrary to other types of cancer, PETs are highly vascularised, but poorly angiogenic tumours. As they progress, VEGF expression is lost and MVD significantly decreases. The regulation of HIF signalling appears to be specific in pancreatic endocrine tumours.

British Journal of Cancer (2005) 92, 94-101. doi:10.1038/sj.bjc.6602245 www.bjcancer.com

Published online 23 November 2004

(c) 2005 Cancer Research UK

Keywords: pancreas; endocrine tumours; angiogenesis; Hypoxia; HIF

Tumorigenesis is critically dependent on the development of a vascular supply and the regulators of blood vessel growth have been shown to play a coordinated role in the progression of a variety of tumours (Bergers and Benjamin, 2003). Normal endocrine tissues and endocrine-derived tumours are characteristically highly vascular and possess a dense and specialised permeable microvascular endothelium. Endocrine cells overproduce the angiogenic peptide vascular endothelial growth factor (VEGF), which is likely to play an important role in the angiogenic process associated with endocrine tumorigenesis (Christofori et al, 1995; Terris et al, 1998; Katoh, 2003). Moreover, they also express specific endothelial cell mitogens, such as endocrine-gland-derived VEGF, (EG-VEGF) that may function in a complementary manner (LeCouter et al, 2001). However, the local and highly specific

* Correspondence: Dr A Couvelard; E-mail: anne.couvelard@bjn.ap-hop-paris.fr

Received 20 May 2004; revised 20 September 2004; accepted 28 September 2004; published online 23 November 2004 mechanisms acting to regulate the angiogenic process associated with endocrine tumorigenesis are poorly understood.

Hypoxia and the hypoxia-inducible factor-1 (HIF-1) pathway regulate the expression of a diverse group of genes that promote tumour growth and are involved in tissue invasion, angiogenesis, cell proliferation, glycolysis and $\mathrm{pH}$ regulation (Semenza, 2001; Wykoff et al, 2001; Harris, 2002; Maxwell and Ratcliffe, 2002; Pugh and Ratcliffe, 2003). Under normal conditions, the HIF- $1 \alpha$ subunit is hydroxylated by proline hydroxylase in a reaction requiring oxygen, undergoes ubiquitination by the von Hippel-Lindau (VHL) protein and is then rapidly degraded in the proteosome. Under conditions of hypoxia in many cancers, HIF- $1 \alpha$ cannot be degraded and increases in the nucleus, leading to the upregulation of many hypoxia-response proteins, such as VEGF or EG-VEGF and carbonic anhydrase 9 (CA9) (Pastorekova et al, 1992; Opavsky et al, 1996; Wykoff et al, 2000; Loncaster et al, 2001; Hui et al, 2002). The Hif- $2 \alpha$ subunit shows properties similar to Hif- $1 \alpha$, but is mainly expressed in the stromal macrophages, and may mediate a different response to hypoxia (Talks et al, 2000). The HIF-1 pathway can also be activated in the VHL syndrome as a 
consequence of somatic VHL gene inactivation (Kaelin, 2002). Pancreatic endocrine tumours can occur both sporadically and as part of a VHL syndrome, which suggests that they may be a good model for studying the potential role of the oxygen-sensing pathway in endocrine tumours.

The aim of this study was to establish the expression pattern of VEGF, HIF- $1 \alpha$, HIF- $2 \alpha$ and CA9 in a series of pancreatic endocrine tumours and to correlate the level of expression with clinicopathological charateristics, angiogenesis and survival.

\section{MATERIAL AND METHODS}

\section{Patients and tissues (Table 1)}

Paraffin-embedded blocks from 45 pancreatic endocrine tumours (PET) were retrieved, from 45 patients (37 patients undergoing surgery, seven patients undergoing diagnostic biopsy and one autopsy) followed at the Beaujon hospital between 1995 and 2001. Surgery consisted of splenopancreatectomy in 17 patients, pancreaticoduodenectomy in 12 and limited resection of the pancreatic body and/or neck $(n=4)$ or tail $(n=4)$. Biopsy specimen included five from liver metastases and two from pancreatic tumours. One block was selected for each case, containing the tumour and the peripheral nontumoral pancreas when possible in large pancreatic resections $(n=33)$. The nontumoral pancreas consisted of chronic pancreatitis associated with areas of normal pancreas in 24 cases. Tissue sections $(4 \mu \mathrm{m})$ were cut and flanking sections from each tumour sample were studied for the expression of VEGF, HIF- $1 \alpha$, HIF- $2 \alpha$, CA9 and CD34.

The clinicopathological characteristics of the 45 cases are summarised in Table 1. Survival data were available for 43 out of 45 patients. One patient who died within 1 month after operation was excluded to avoid bias from peri-operative death. The median follow-up of surviving patients at the time of analysis was 32 months (range 2-86 months). The following histopathological and clinical data were recorded for surgical or autopsy material: age, sex, functional status of tumours (hormonal syndrome (insulinoma, glucagonoma, somatostatinoma, VIPoma) or not), VHL disease and type 1 multiple endocrine neoplasia (MEN1) syndrome. Tumours were classified in four groups according to the WHO 2000 criteria (benign well-differentiated endocrine tumours, reported as WHO-1, well-differentiated endocrine tumours of uncertain behaviour, reported as WHO-2, welldifferentiated endocrine carcinomas, reported as WHO-3, and poorly differentiated endocrine carcinomas, reported as WHO-4) (Solcia et al, 2000). Most of the WHO-4 cases corresponded to biopsy specimen because such cases which require chimiotherapy are not surgically resected. VHL cases corresponded to WHO-1 $(n=1)$, WHO-2 $(n=3)$ or WHO-3 $(n=4)$ tumours. In addition, the size of the tumour, presence of necrosis, presence of a fibrotic focus, number of mitoses (per 10 high power field), percentage of cell nuclei stained for Ki-67 (MIB-1 antibody), vascular embolism (not evaluated in the biopsy samples), lymph node metastasis and liver metastasis were also recorded. Tumours with $\leqslant 5$ mitoses per 10 high-power field or $\leqslant 5 \% \mathrm{Ki}-67$-positive cells were considered at a low mitotic rate or low proliferative index, respectively. In accordance with previously reported studies, both poorly differentiated tumours and tumours with high proliferative index were associated with poorer survival in our series $(P<0.0001)$ (Gentil Perret et al, 1998; Madeira et al, 1998).

\section{Immunohistochemistry}

Antibodies and immunohistochemical techniques The VEGF, HIF- $1 \alpha$, HIF- $2 \alpha$, CA9, Ki-67 proteins and CD34 antigen were detected using the following murine monoclonal antibodies: VG1 (that detects the 121, 165 and 189 VEGF isoforms), ESEE 122, Ep
Table I Patients demographics and main pathological features

\begin{tabular}{|c|c|}
\hline Characteristics & $\begin{array}{c}\text { No of } \\
\text { patients } \\
(n=45)\end{array}$ \\
\hline \multicolumn{2}{|l|}{ Age (years) } \\
\hline$<40$ & 12 \\
\hline$>40$ & 33 \\
\hline \multicolumn{2}{|l|}{ Sex } \\
\hline Male & 22 \\
\hline Female & 33 \\
\hline \multicolumn{2}{|l|}{ VHL disease } \\
\hline $\mathrm{VHL}+$ & 8 \\
\hline VHL- & 37 \\
\hline \multicolumn{2}{|l|}{ Functional Syndrome } \\
\hline Present & 7 \\
\hline Absent & 38 \\
\hline \multicolumn{2}{|l|}{ Size $(\mathrm{mm})$} \\
\hline$<30$ & 25 \\
\hline$>30$ & 20 \\
\hline \multicolumn{2}{|l|}{ Classification according to WHO 2000} \\
\hline WHO-stage $\mathrm{I}=$ benign endocrine tumours & 8 \\
\hline WHO-stage $2=$ endocrine tumours of incertain behaviour & 11 \\
\hline WHO-stage $3=$ well-differentiated endocrine carcinomas & 18 \\
\hline WHO-stage $4=$ poorly differentiated endocrine carcinomas & 8 \\
\hline \multicolumn{2}{|l|}{ Necrosis } \\
\hline No & 33 \\
\hline $\mathrm{NI}$ & 12 \\
\hline \multicolumn{2}{|l|}{$\mathrm{Ki}-67$ or mitoses } \\
\hline$\leqslant 5$ & 18 \\
\hline$>5$ & 17 \\
\hline \multicolumn{2}{|l|}{ Lymph node status } \\
\hline No & 27 \\
\hline NI & 18 \\
\hline \multicolumn{2}{|l|}{ Liver metastasis } \\
\hline Mo & 30 \\
\hline MI & 15 \\
\hline \multicolumn{2}{|l|}{ Duration of follow-up (months) } \\
\hline Median & 32 \\
\hline Range & $2-86$ \\
\hline Lost to follow-up & 2 \\
\hline Death & 11 \\
\hline
\end{tabular}

190b, M75, MIB-1 (Dako) and QBEND10 (Dako), respectively (Turley et al, 1998; Talks et al, 2000; Hui et al, 2002). The methodology used is as described previously (Turley et al, 1998; Hui et al, 2002). Briefly, sections were first placed in a $60^{\circ} \mathrm{C}$ oven for $10 \mathrm{~min}$ before deparaffinisation in Citroclear twice for $12 \mathrm{~min}$ and rehydratation. Antigen retrieval consisted of pressure cooking for $3 \mathrm{~min}$ in Tris-EDTA ( $\mathrm{pH}$ 9) for VEGF, Ki-67 and CD34, and $60^{\circ} \mathrm{C}$ waterbath overnight in $1 \mathrm{~mm}$ Tris-EDTA ( $\mathrm{pH}$ 9) for HIF- $1 \alpha$ and HIF- $2 \alpha$. Permeabilisation was performed with $0.2 \%$ triton X100 for 10 min for HIF- $1 \alpha$ and HIF- $2 \alpha$. Endogenous peroxidase was then quenched with Dako peroxidase block solution applied for 5 min. The primary antibody was applied, rinsed in PBS and then the secondary polymer from the Envision HRP kit (Dako) was applied for $30 \mathrm{~min}$. After the slides were washed in PBS, the colour was developed by a 5 -min incubation with $3,3^{\prime}$-diaminobenzidine solution (Dako). Sections were counterstained with haematoxylin 
and mounted. PBS was substituted for primary antibody as the negative control. Positive controls consisted of serum in blood vessel lumen (VEGF), HIF- $1 \alpha$ transfected COS- 1 cells (HIF- $1 \alpha$ ), known positive tumour (HIF-2 $\alpha$ ) and clear cell renal carcinoma (CA9).

Immunohistochemical double staining of CD34 and Ki-67 was performed to detect proliferating endothelial cells. The immunohistochemical reaction against Ki-67 was revealed in brown with $3,3^{\prime}$-diaminobenzidine and was followed by the immunohistochemical reaction against CD34 revealed in red with amino ethyl carbazole. The brown nuclei of proliferating endothelial cells are superimposed on the red colour of the cytoplasms.

Scoring methods All slides were evaluated independently by two investigators ( $\mathrm{AC}$ and $\mathrm{KG}$ ) who were blinded to the patients' clinical data. The differences in evaluation between the two observers were resolved at a conference microscopy. The specimens were scanned at a low optical power $(\times 40)$ to study the tissue distribution of staining and at a high optical power $(\times 250)$ to study the cellular staining patterns. The percentage of cells with positive reactivity was scored. The pattern of expression (cytoplasmic, membranous or nuclear) and the intensity (negative scored as 0 , weak scored as 1 , moderate scored as 2 and strong scored as 3) were noted. A cytoplasmic score was calculated by multiplying the percentage of cytoplasmic stained cells by their staining intensity. For HIF- $2 \alpha$ the presence or absence of positively stained stroma was noted. The staining of the stroma was not evaluated in biopsy cases because of the small size of these tissue samples.

Microvessel counting Two areas of high vascularisation were chosen for microvessel counting at a low optical power $(\times 10$ objective) after CD34 staining. The final microvessel density (MVD) was the mean value of three appraised high power fields $\left(\times 25\right.$ objective, Leitz, field area $\left.0.442 \mathrm{~mm}^{2}\right)$ in each area of high vascularisation (total area: $2.65 \mathrm{~mm}^{2}$ ). The vessel counts were very homogeneous in all tumours and six fields were sufficient to obtain reproducible results. In biopsy samples, the entire biopsy was evaluated for microvessel counting. Vessels with a clearly defined lumen or well-defined linear vessel shape were taken into account for counting. Tumours with $<200$ microvessels $\mathrm{mm}^{-2}$ were considered as low microvessel density, whereas those with $>200$ microvessels $\mathrm{mm}^{-2}$ were considered as high microvessel density.

Proliferating endothelial cells counting The percentage of proliferating endothelial cells was determined in areas of high vascularisation using a $\times 40$ objective. In all, 300 endothelial cells were recorded as positive or negative for $\mathrm{Ki}-67$ in each tumour. In biopsy samples, the entire biopsy was evaluated for proliferating endothelial cells counting.

\section{Statistical analysis}

Fisher's exact tests examined relationships between categorical tumour variables. Mann-Whitney nonparametric tests were utilised to compare categorical with continuous tumour variables where the number of categories was two; where the number of categories was greater than two, Kruskall-Wallis nonparametric tests were used instead. Spearman rank correlations were used to investigate relationships between continuous patient and tumour variables. $P$-values of $<0.05$ were considered significant. Survival rates were calculated from the time of resection until the end of follow-up period (July 2003) and curves were plotted using the method of Kaplan and Meier. The log-rank test was used to evaluate differences between life tables. These analyses were performed using Statview 4.5 statistical analysis software (Abacus Concepts Inc., CA, USA).

\section{RESULTS}

\section{VEGF expression}

In nontumoral pancreas, VEGF was detected in islets with a strong intensity in all cases. Normal or reactive hyperplastic ducts and acini were persistently negative.

Tumour cells had positive cytoplasmic staining in $33(73 \%)$ patients (weak intensity in 18 cases, moderate intensity in 10 cases and strong intensity in four). The VEGF score ranged from 0 to 210 (mean 55; median 30).

VEGF expression correlated negatively with WHO disease stage (Figures 1A, B and 2). Five of eight patients $(62 \%)$ with negative staining for VEGF had WHO-stage 4, five out of 18 (28\%) WHOstage 3 and two out of 19 (11\%) WHO-stage $1-2$. The VEGF score was significantly higher in tumours with a low index of proliferation or mitosis count, no necrosis, no fibrotic focus and a high microvascular density (although this did not reach significant levels; $P=0.06$ ). No difference in VEGF expression was observed in endocrine tumours associated with VHL or not (see values in Table 2). There was no association between VEGF expression and survival.

\section{HIF- $1 \alpha$ expression}

In nontumoral pancreas, HIF- $1 \alpha$ was detected in islets with a high cytoplasmic intensity in all cases and was expressed by nerves and neurons.
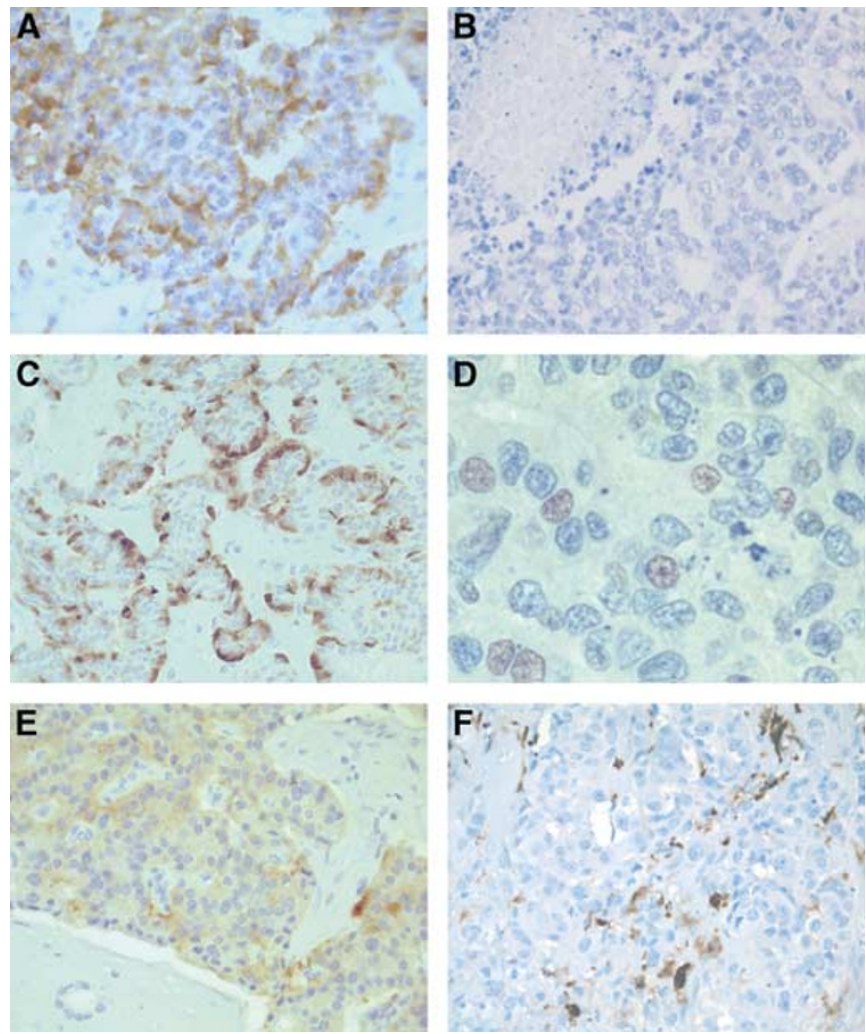

Figure I Immunohistochemical expression of VEGF, HIF- $\mid \alpha$ and $H I F-2 \alpha$ by WHO-stage I (A, C. E and $\mathbf{F})$ and $\mathrm{WHO}$-stage 4 (B. D) PETs. (A. B VEGF is highly expressed in a WHO stage- I PET $(\mathbf{A})$ and negative in a WHO-stage 4 PET (B). (C. D) HIF- I $\alpha$ cytoplasmic expression is strong in a WHO-stage I PET (C). HIF- I $\alpha$ nuclear expression is detected in a WHOstage 4 PET (D). (E, F) HIF-2 $\alpha$ cytoplasmic (E) and stromal (F) expression is detected in a WHO-stage I PET. Immunoperoxidase and haematoxylin nuclear counterstaining; original magnifications: $\mathbf{A} \times 250$; $\mathbf{B}, \times 250$; $\mathbf{C}$ $\times 150 ; \mathbf{D} \times 500 ; \mathbf{E}, \times 200 ; \mathbf{F}, \times 250$. 


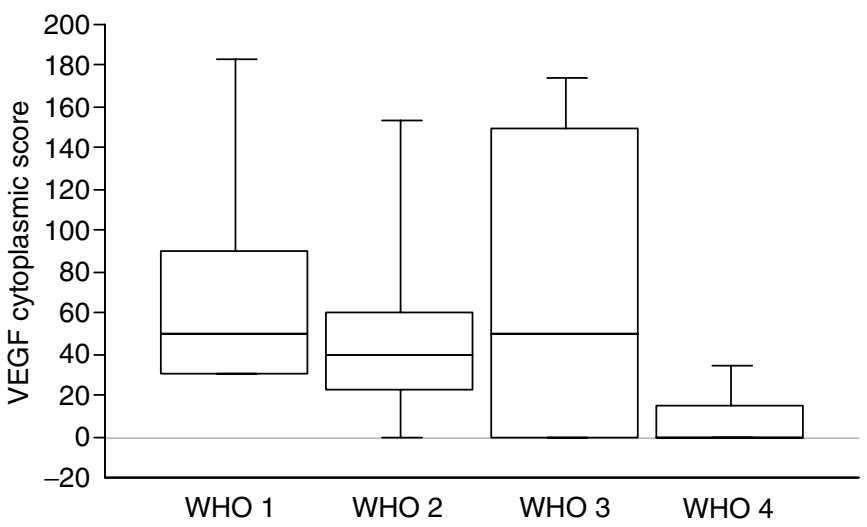

Figure 2 Box plot of VEGF cytoplasmic score stratified according to the WHO classification. Differences between groups were statistically significant $(P=0.03)$.

Table 2 Cytoplasmic and nuclear expression of VEGF, HIF- $\mid \alpha, H I F-2 \alpha$, CA9 and values of microvessel density according to $\mathrm{VHL}$ status in welldifferentiated tumours $(n=37)$

\begin{tabular}{llccc}
\hline & & $\begin{array}{r}\text { VHL+ } \\
(\mathbf{n}=\mathbf{8})\end{array}$ & $\begin{array}{c}\text { VHL- } \\
(\mathbf{n}=\mathbf{2 9 )}\end{array}$ & $\boldsymbol{P}$ \\
\hline VEGF & Mean cytoplasmic score \pm s.d. & $60 \pm 55$ & $66 \pm 64$ & NS \\
HIF-I $\alpha$ & Mean cytoplasmic score \pm s.d. & $95 \pm 70$ & $215 \pm 83$ & 0.03 \\
& Mean nuclear \% \pm s.d. & $12 \pm 9.4$ & $6.3 \pm 7.7$ & 0.04 \\
HIF-2 $\alpha$ & Mean cytoplasmic score \pm s.d. & $10 \pm 20$ & $14 \pm 28$ & NS \\
& Mean nuclear \% \pm s.d. & $1.4 \pm 1.8$ & $2 \pm 5.5$ & NS \\
CA9 & Mean cytoplasmic score \pm s.d. & $73 \pm 50$ & $2.7 \pm 14.6$ & 0.0001 \\
CD34 & Microvessel density (vessels mm ${ }^{-2}$ ) & $563 \pm 189$ & $215 \pm 82$ & 0.02 \\
\hline
\end{tabular}

$\mathrm{VHL}+$ : von Hippel-Lindau disease cases; $\mathrm{VHL}-$ : cases without von Hippel-Lindau disease; s.d.: standard deviation; NS: nonsignificant.

The majority of endocrine tumours expressed high levels of cytoplasmic HIF- $1 \alpha$. Only four cases (9\%) showed no HIF- $1 \alpha$ cytoplasmic staining. Percentage values varied from 0 to $100 \%$ of tumour cells (mean cytoplasmic score 167; median 180). The intensity of cytoplasmic staining was moderate or strong in 35 cases. Nuclear staining was detected in 31 out of $45(69 \%)$ of the cases (percentage values ranged from 0 to $50 \%$; mean $9.3 \%$; median $5 \%)$.

HIF- $1 \alpha$ cytoplasmic expression was significantly higher in welldifferentiated benign tumours (Figure 1C) than in tumours of uncertain behaviour or carcinomas (see values in Figure 3). The HIF- $1 \alpha$ cytoplasmic score was significantly lower in poorly differentiated tumours, tumours of large size, with high mitosis count, necrosis, lymph node metastasis, low MVD or VHL disease (see values in Table 2).

HIF- $1 \alpha$ nuclear expression was significantly higher in carcinomas (Figure 1D) than in tumours of uncertain behaviour and in benign tumours (Figure 4). Presence of HIF- $1 \alpha$ nuclear expression was significantly associated with poor tumour differentiation, large tumour size, higher mitosis count or index of proliferation, presence of necrosis, of a fibrotic focus, of liver metastasis, low MVD and VHL disease (mean values in Table 2). Presence of HIF$1 \alpha$ nuclear expression was associated with shorter survival, although this was not statistically significant $(P=0.06)$.

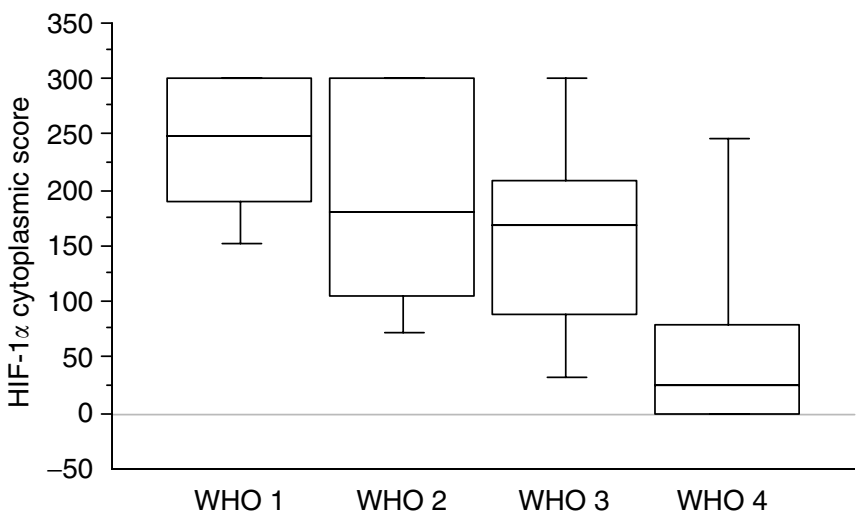

Figure 3 Box plot of HIF- $\mid \alpha$ cytoplasmic score stratified according to the $\mathrm{WHO}$ classification. Differences between groups were statistically significant $(P=0.008)$.

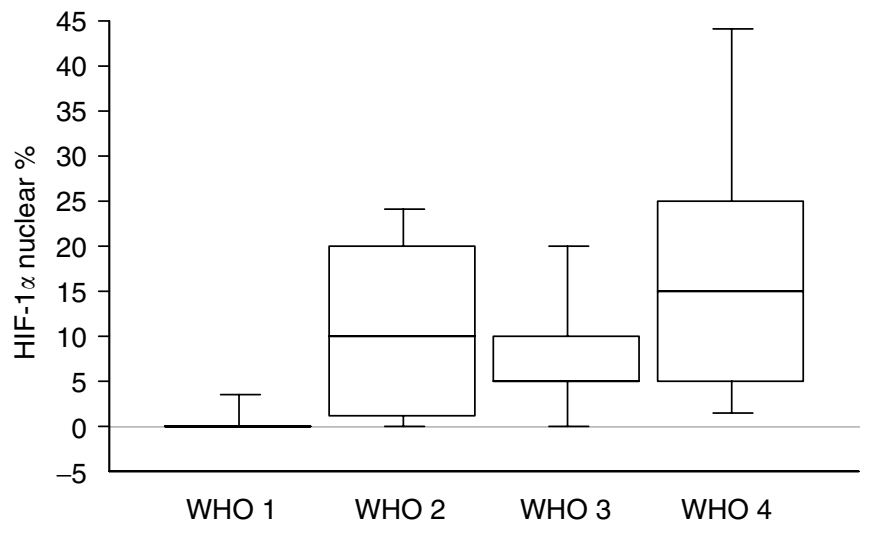

Figure 4 Box plot of HIF- I $\alpha$ nuclear expression stratified according to the WHO classification. Differences between groups were statistically significant $(P=0.00 \mathrm{I})$.

\section{HIF-2 $\alpha$ expression}

Nontumoral pancreatic islets showed a weak cytoplasmic HIF- $2 \alpha$ staining. Tumour cells were found to have cytoplasmic staining (Figure 1E) in 13 cases (29\%) and nuclear stainings in $13(29 \%)$ cases. Both stainings were not statistically associated. Percentage staining of cytoplasm varied from 5 to $80 \%$ of PET cells (mean cytoplasmic score 13; median 0 ). Nuclear staining was weak (range 1-30\%; mean $1.5 \%$; median 0 ).

Stromal HIF- $2 \alpha$ expression was observed in 12 out of 38 (32\%) of cases, detected in the cytoplasm of tumour-associated macrophages which were present in moderate to large numbers (Figure 1F). None or few positive macrophages were considered as negative.

There was no significant association of HIF- $2 \alpha$ staining in tumour cells or in macrophages with histopathological variables, MVD, VHL disease or survival.

\section{CA9 expression}

In nontumoral pancreatic tissue, CA9 was detected in normal or reactive hyperplastic ducts in 22 cases and in acini in 12 cases. Islets were negative. Expression of CA9 in the normal pancreas was stronger in areas of pancreatitis close to invading tumours.

CA9 expression was cytoplasmic (of weak or moderate intensity) in nine tumours or membranous (of moderate or strong intensity) in 12 tumours. No CA9 staining was seen in 25 out of $45(53 \%)$ of 
98
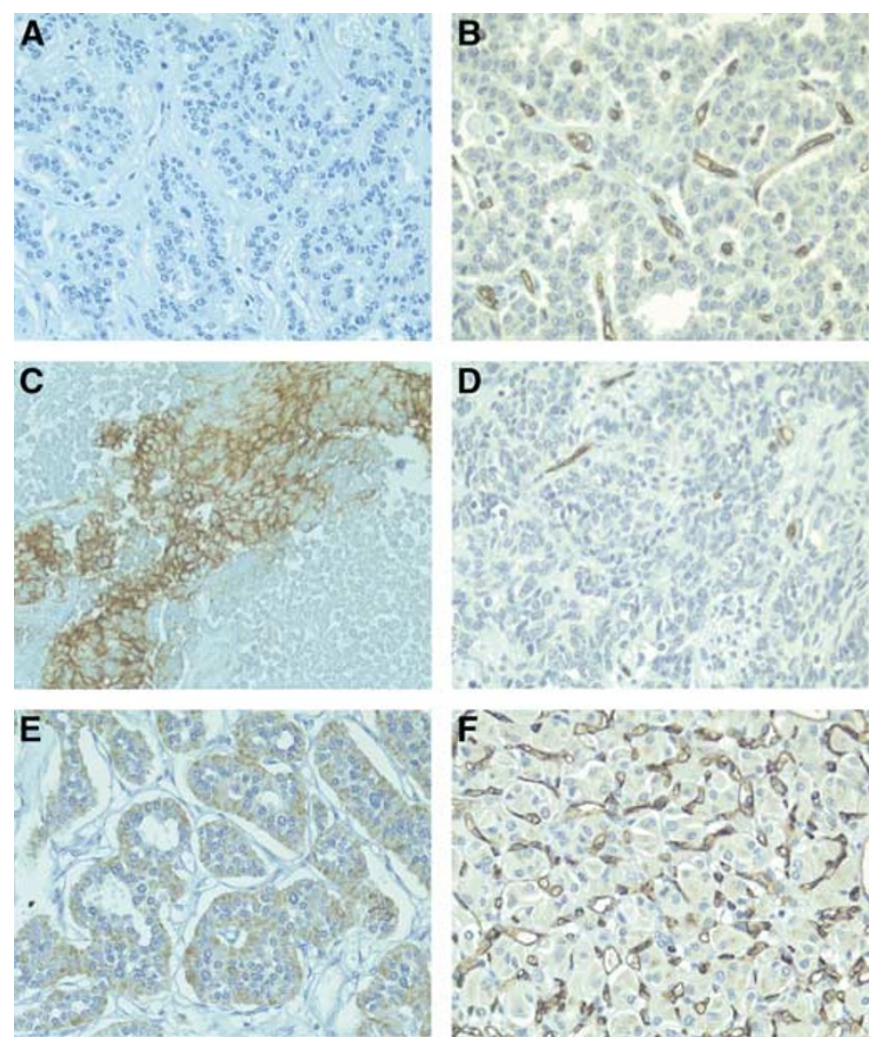

Figure 5 Immunohistochemical expression of CA9 and CD34 by WHO-stage I (A, B) and WHO-stage 4 (C, D) pancreatic endocrine tumours and by $\mathrm{VHL}$ cases $(\mathbf{E}, \mathbf{F})$. (A, C, E) CA9 is not detected in most well-differentiated PETs $(\mathbf{A})$. Its expression is strong and membranous around areas of necrosis in WHO-stage 4 PETs $(\mathbf{C})$ and cytoplasmic diffuse in $\mathrm{VHL}$ cases $(\mathbf{E})$. (B, D, F) CD34+ capillaries are numerous in $\mathrm{WHO}$ stage I PETs (B) and scattered in WHO-stage 4 PETs (D). Microvascular density is very high in $\mathrm{VHL}$ cases $(\mathbf{F})$. Immunoperoxidase and haematoxylin nuclear counterstaining; original magnifications: A $\times 150$; B, $\times 250$; C $\times 200 ; \mathbf{D}, \times 150 ; \mathbf{E}, \times 200 ; \mathbf{F}, \times 250$.

tumours (Figure 5A). Percentage values of membranous or cytoplasmic staining varied from 5 to $60 \%$ (mean score 22; median 0 ) and from 5 to $80 \%$ (mean score 15 ; median 0 ) of tumour cells, respectively. Fibroblasts were positive in only one case, in the tumoral stroma adjacent to a fibrotic area, in a case containing membranous CA9 + tumour cell areas.

CA9 membranous expression (Figure 5C) was significantly higher in WHO-stage 4 or poorly differentiated tumours (see values in Figure 6). Out of 12 PETs with CA9 membranous staining, 10 contained necrosis either extensive or focal and CA9 expression was confined around areas of necrosis in seven of those 10 cases. Membranous expression of CA9 was significantly higher in large tumours, in tumours with the presence of a fibrotic focus, a high mitotic count or proliferation index, liver metastases, low MVD and shorter survival $(P=0.0004$; Figure 7$)$.

CA9 cytoplasmic expression (Figure 5E) was significantly higher in tumours associated with VHL disease (values in Table 2) and in tumours with a greater microvascular density. Cytoplasmic staining was detected in eight out of eight VHL patients, whereas 36 out of 37 non-VHL patients were negative.

\section{Microvessel counting}

The microvessel density ranged from 26 to 792 vessels $\mathrm{mm}^{-2}$ (mean 311; median 276). The mean values, (see Figure 8), decreased with disease progression according to WHO classifica-

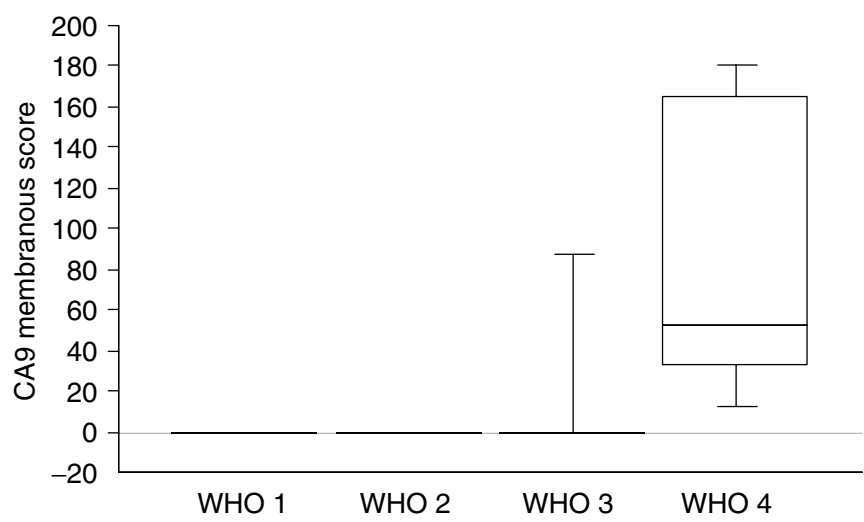

Figure 6 Box plot of CA9 membranous expression stratified according to the $\mathrm{WHO}$ classification. Differences between groups were statistically significant $(P=0.000 \mathrm{I})$.

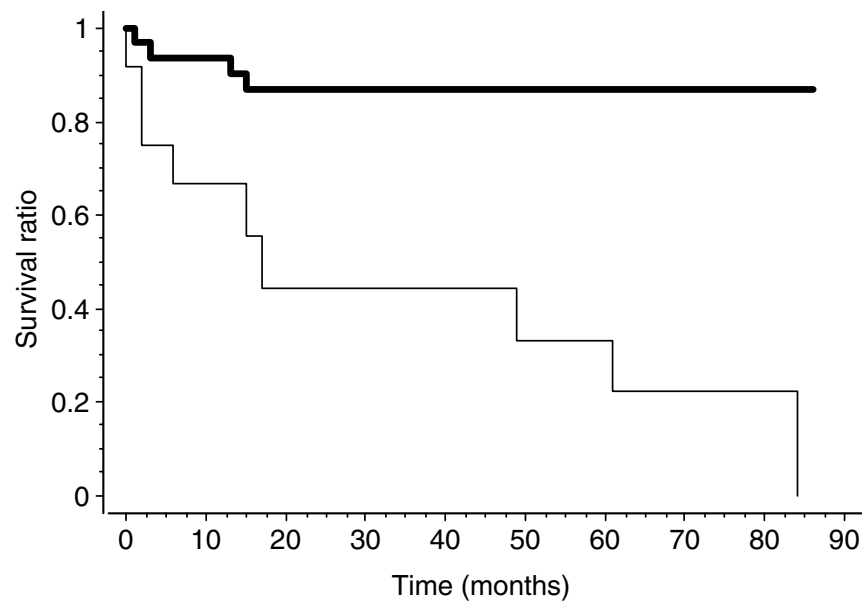

Figure 7 Survival curves according to Kaplan-Meier for 43 of the 45 patients of the study group according to CA9 membranous expression (thin line) or absence of expression (bold line); $P=0.0004$.

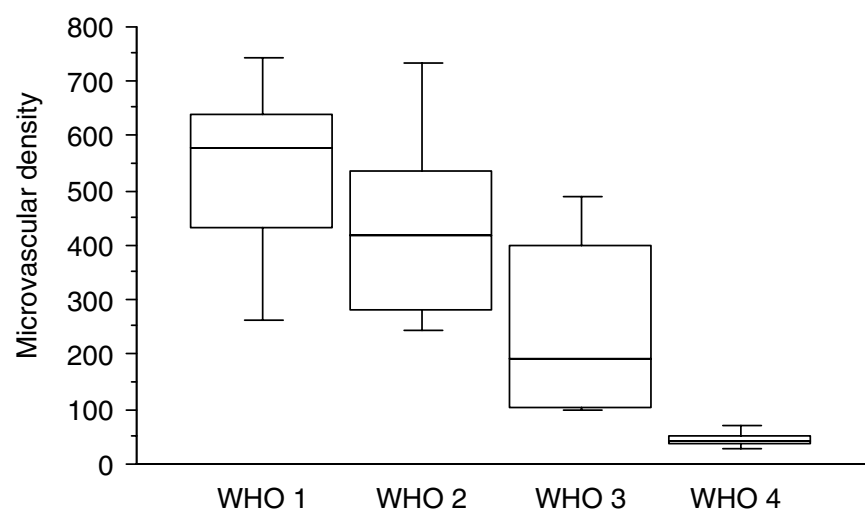

Figure 8 Box plot of MVD recorded in hotspots stratified according to the WHO classification. Differences between groups were statistically significant $(P=0.000 \mathrm{I})$.

tion (Figure 5B and D). All well-differentiated tumours, both benign and of uncertain behaviour, had $>200$ vessels $\mathrm{mm}^{-2}$ (in contrast to the nine out of 18 well-differentiated carcinomas and eight out of eight poorly differentiated carcinomas, which had counts of less than 200 vessels $\mathrm{mm}^{-2}$ ). The MVD was higher in 


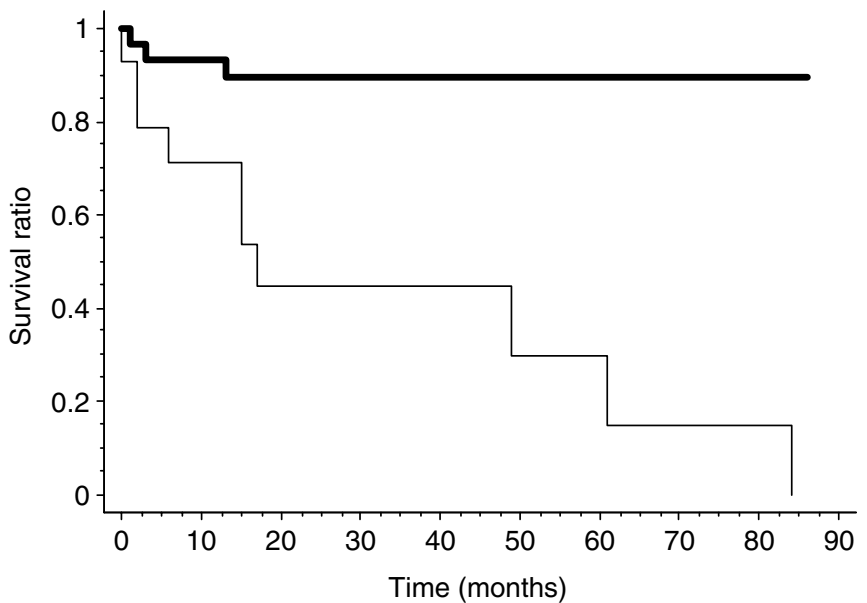

Figure 9 Survival curves according to Kaplan-Meier for 43 of the 45 patients of the study group according to MVD $<200 \mathrm{~mm}^{-2}$ (thin line) or $>200 \mathrm{~mm}^{-2}$ (bold line); $P=0.0001$.

large tumours, in tumours with necrosis, a fibrotic focus, a high mitotic count or MIB1 index and presence of liver metastasis. A high MVD was also associated with VHL cases (Figure 5F and values in Table 2). Low tumour MVD $\left(<200\right.$ vessels $\left.\mathrm{mm}^{-2}\right)$ was significantly associated with shorter survival $(P=0.001$; Figure 9$)$.

\section{Proliferating endothelial cells counting}

There was a mean endothelial proliferation index of 3.7\% (range $0-9.6 \%$; median 3.8\%). Endothelial proliferation did not differ significantly between the different groups of the WHO classification.

\section{Co-expression of markers}

Tumour HIF- $1 \alpha$ nuclear expression was significantly correlated with that of CA9 membranous expression and low MVD. High cytoplasmic HIF- $1 \alpha$ expression was correlated significantly with VEGF expression and high MVD.

\section{DISCUSSION}

Currently, standard histology coupled with evaluation of mitotic rates and proliferation index are essential in helping to predict the biological behaviour of endocrine tumours and select appropriate treatment strategies as a function of WHO disease stage. Such methods are not always reliable and many tumours fall in-between tumour stage, indicating that better markers of tumour aggressiveness are required. The fact that endocrine tumours are highly vascular in nature renders analysis of angiogenesis as a prognostic factor highly pertinent. To date, few data evaluating angiogenesis in the progression of endocrine neoplasms are available and mostly applies to pituitary tumours where results remain equivocal (Erroi et al, 1986; Jugenburg et al, 1995; Sasano et al, 1998; Turner et al, 2000a-c; Bernini et al, 2002). A high intratumoral MVD was demonstrated in our study, much greater than those reported in any type of tumours (Goulding et al, 1995; Fox, 1997; Prall et al, 2003). However, we found a wide range of MVD values according to the malignant potential, undifferentiated carcinomas showing a 10 times lower MVD than benign tumours. A negative correlation has previously been described between MVD and advanced pituitary adenomas and carcinomas (Erroi et al, 1986; Jugenburg et al, 1995; Bernini et al, 2002), and a recent study demonstrates comparable results in PETs (Marion-Audibert et al, 2003). In our series, a high MVD was found to correlate with previously established markers of good prognosis (small tumour size, welldifferentiated tumours, low mitotic count and low proliferation index) (Solcia et al, 2000; Hochwald et al, 2002). Moreover, patients with low MVDs had a significantly shorter survival $(P=0.0001)$ and a higher risk of metastatic dissemination. These observations appear to be tumour-specific and contrast with those seen previously in most other epithelial cancers (Weidner et al, 1992; Maeda et al, 1995; Weidner, 1995, 1998; Pezzella et al, 1997; Ellis et al, 1998; Eberhard et al, 2000). The specific vascular profile observed in PETs may help to predict their prognosis. In fact, prediction of the biological behaviour of PETs is difficult by histological criteria alone and patients with metastatic disease may have a prolonged survival. MVD may help in predicting long-term prognosis in these patients. As MVD has also been shown to be correlated with contrast enhancement on computed tomography in PET (unpublished personal data), use of such a marker would not be limited to post-operative scenarios.

We demonstrate in this study a specific pattern of expression of VEGF, HIF- $1 \alpha$ and HIF- $2 \alpha$ in pancreatic endocrine tumours. VEGF is upregulated in many human tumours and its expression has usually been correlated with a high microvascular density and poor clinical outcome (Itakura et al, 1997; Seo et al, 2000; Hui et al, 2002; Niedergethmann et al, 2002). In the present study, VEGF expression detected in $78 \%$ of PETs, mainly in highly vascularised benign cases, is in accordance with previous results (Terris et al, 1998; La Rosa et al, 2003). An interesting finding is that VEGF expression was significantly lower in undifferentiated poorly vascularised cases.

HIF- $1 \alpha$ and HIF- $2 \alpha$ are known to mediate the induction of the HIF-regulated genes. Their nuclear expression has been demonstrated in several tumours and is associated with an aggressive phenotype (Zhong et al, 1999; Birner et al, 2000; Giatromanolaki et al, 2001). Expression of such proteins in perinecrotic areas supports evidence for microenvironmental mechanisms of activation secondary to hypoxia (Talks et al, 2000). To date, their expression has never been described in endocrine tumours. We have demonstrated a cytoplasmic distribution of HIF- $1 \alpha$ in $91 \%$ of PETs and HIF- $2 \alpha$ in $29 \%$, which has rarely been reported in other human tumours (Zhong et al, 1999; Talks et al, 2000; Zagzag et al, 2000; Giatromanolaki et al, 2001; Hui et al, 2002). This expression appears not to be related to a local hypoxic process, since there is a high number of microvessels in these tumours. Moreover, it is not known whether these cytoplasmic molecules are active or not. We also demonstrated, as for VEGF, the cytoplasmic expression of HIF- $1 \alpha$ and HIF- $\alpha \alpha$ in normal pancreatic islets. This specific phenotype, which persists in benign PETs, is progressively lost with disease progression. Endocrine blood vessels are numerous and stabilised in normal endocrine tissue and probably retain these properties in well-differentiated tumours. This is supported by the low index of proliferation of endothelial cells, which suggests that despite a high MVD there is a low neoangiogenesis in these tumours. As suggested by the observation of low MVD in advanced carcinomas, vessels progressively regress during tumour progression. This is consistent with recently described animal models showing loss of vessel differentiation and a decrease in vessel density in pancreatic endocrine tumours as compared to the normal islets (Ryschich et al, 2002). Expression of antiangiogenic factors probably plays a role in this phenomenon (Holash et al, 1999; Bergers and Benjamin, 2003; Carmeliet, 2003). In advanced PETs, low MVD associated with an increase in tumour-cell proliferation may, beyond the limit of oxygen diffusion, lead to hypoxia and activation of CA9. This pattern of expression resembles that of most other carcinomas with strong and membranous positivity for CA9 at the periphery of areas of necrosis (Zhong et al, 1999; Wykoff et al, 2000; Loncaster et al, 2001; Hui et al, 2002). CA9 expression is consistent with the upregulation of HIF- $1 \alpha$ nuclear expression in poorly differentiated 
tumours, recalling the situation observed in most carcinomas studied so far. The value of membranous CA9 was underlined by its strong associations with factors of poor outcome (tumour size and differentiation), but especially with a shorter survival $(P=0.0004)$. A diffuse cytoplasmic CA9 pattern of expression as a specific feature of VHL cases was observed in our series, differing from the strong membranous staining that we found in undifferentiated tumours. In most tumours, CA9 is a transmembrane enzyme with an extracellular active site, linked to aggressive tumour behaviour (Opavsky et al, 1996; Wykoff et al, 2000; Loncaster et al, 2001; Hui et al, 2002; Turner et al, 2002). The role of cytoplasmic CA9, if any, is probably different in PETs. It does not appear to be hypoxia-related, as it is correlated to VHL disease in which PETs possess a significantly higher MVD but is likely to be related to loss of VHL function. In cases of VHL disease, hypoxia-inducible gene expression is constitutively upregulated (Kaelin, 2002). This is consistent with the frequency of nuclear HIF- $1 \alpha$ that we found in VHL-related PETs. In renal cell carcinomas, VHL inactivation occurs in most sporadic cases,

\section{REFERENCES}

Bergers G, Benjamin LE (2003) Tumorigenesis and the angiogenic switch. Nat Rev Cancer 3: 401-410

Bernini GP, Moretti A, Bonadio AG, Menicagli M, Viacava P, Naccarato AG, Iacconi P, Miccoli P, Salvetti A (2002) Angiogenesis in human normal and pathologic adrenal cortex. J Clin Endocrinol Metab 87: $4961-4965$

Birner P, Schindl M, Obermair A, Plank C, Breitenecker G, Oberhuber G (2000) Overexpression of hypoxia-inducible factor lalpha is a marker for an unfavorable prognosis in early-stage invasive cervical cancer. Cancer Res 60: $4693-4696$

Blouw B, Song H, Tihan T, Bosze J, Ferrara N, Gerber HP, Johnson RS, Bergers G (2003) The hypoxic response of tumors is dependent on their microenvironment. Cancer Cell 4: 133-146

Carmeliet P (2003) Angiogenesis in health and disease. Nat Med 9: 653-660

Christofori G, Naik P, Hanahan D (1995) Vascular endothelial growth factor and its receptors, flt- 1 and flk-1, are expressed in normal pancreatic islets and throughout islet cell tumorigenesis. Mol Endocrinol 9: $1760-1770$

Chung DC, Smith AP, Louis DN, Graeme-Cook F, Warshaw AL, Arnold A (1997) A novel pancreatic endocrine tumor suppressor gene locus on chromosome 3p with clinical prognostic implications. J Clin Invest 100: 404-410

Eberhard A, Kahlert S, Goede V, Hemmerlein B, Plate KH, Augustin HG (2000) Heterogeneity of angiogenesis and blood vessel maturation in human tumors: implications for antiangiogenic tumor therapies. Cancer Res 60: $1388-1393$

Ellis LM, Walker RA, Gasparini G (1998) Is determination of angiogenic activity in human tumours clinically useful? Eur J Cancer 34: 609-618

Erroi A, Bassetti M, Spada A, Giannattasio G (1986) Microvasculature of human micro- and macroprolactinomas. A morphological study. Neuroendocrinology 43: 159-165

Fox SB (1997) Tumour angiogenesis and prognosis. Histopathology 30: $294-301$

Gentil Perret A, Mosnier JF, Buono JP, Berthelot P, Chipponi J, Balique JG, Cuilleret J, Dechelotte P, Boucheron S (1998) The relationship between MIB-1 proliferation index and outcome in pancreatic neuroendocrine tumors. Am J Clin Pathol 109: 286-293

Giatromanolaki A, Koukourakis MI, Sivridis E, Turley H, Talks K, Pezzella F, Gatter KC, Harris AL (2001) Relation of hypoxia inducible factor 1 alpha and 2 alpha in operable non-small cell lung cancer to angiogenic/ molecular profile of tumours and survival. Br J Cancer 85: 881-890

Goulding H, Nik Abdoul Rashid NF, Robertson JF, Bell JA, Elston CW, Blamey RW, Ellis IO (1995) Assessment of angiogenesis in breast carcinoma: an important factor in prognosis? Hum Pathol 26: 1196- 1200

Gumbs AA, Moore PS, Falconi M, Bassi C, Beghelli S, Modlin I, Scarpa A (2002) Review of the clinical, histological, and molecular aspects of pancreatic endocrine neoplasms. J Surg Oncol 81: 45-53, discussion 54

Harris AL (2002) Hypoxia - a key regulatory factor in tumour growth. Nat Rev Cancer 2: $38-47$ resulting in an accumulation of CA9, HIF- $1 \alpha$ and HIF- $2 \alpha$ (Ivanov et al, 1998; Turner et al, 2002). Our results, showing no CA9 accumulation in well-differentiated, non-VHL tumours, are consistent with the fact that VHL mutations have only been reported in the initial progression of a small proportion of PETs (Chung et al, 1997; Moore et al, 2001; Gumbs et al, 2002). Only one PET expressed weak levels of cytoplasmic CA9 without any clinical symptoms of VHL disease in our series. It could be hypothesised that this case may represent a sporadic VHL mutation.

In conclusion, this study shows that as PETs progress there is loss of the baseline VEGF expression and decresead MVD. There is a partial switch to hypoxia pathways in malignant undifferentiated tumours, but with an overall low angiogenic activity. Recent experimental observations have shown the markedly different effects of HIF on tumour biology in different tissues (Blouw et al, 2003). This is the first clinical study to demonstrate such effects in the pancreatic endocrine tumour pathway, confirming the existence of tissue and tumour-specific angiogenesis and pathway of regulation of HIF signalling.
Hochwald SN, Zee S, Conlon KC, Colleoni R, Louie O, Brennan MF, Klimstra DS (2002) Prognostic factors in pancreatic endocrine neoplasms: an analysis of 136 cases with a proposal for low-grade and intermediate-grade groups. J Clin Oncol 20: 2633-2642

Holash J, Wiegand SJ, Yancopoulos GD (1999) New model of tumor angiogenesis: dynamic balance between vessel regression and growth mediated by angiopoietins and VEGF. Oncogene 18: 5356-5362

Hui EP, Chan AT, Pezzella F, Turley H, To KF, Poon TC, Zee B, Mo F, Teo PM, Huang DP, Gatter KC, Johnson PJ, Harris AL (2002) Coexpression of hypoxia-inducible factors 1alpha and 2alpha, carbonic anhydrase IX, and vascular endothelial growth factor in nasopharyngeal carcinoma and relationship to survival. Clin Cancer Res 8: 2595-2604

Itakura J, Ishiwata T, Friess H, Fujii H, Matsumoto Y, Buchler MW, Korc M (1997) Enhanced expression of vascular endothelial growth factor in human pancreatic cancer correlates with local disease progression. Clin Cancer Res 3: 1309-1316

Ivanov SV, Kuzmin I, Wei MH, Pack S, Geil L, Johnson BE, Stanbridge EJ, Lerman MI (1998) Down-regulation of transmembrane carbonic anhydrases in renal cell carcinoma cell lines by wild-type von HippelLindau transgenes. Proc Natl Acad Sci USA 95: $12596-12601$

Jugenburg M, Kovacs K, Stefaneanu L, Scheithauer BW (1995) Vasculature in nontumorous hypophyses, pituitary adenomas, and carcinomas: a quantitative morphologic study. Endocr Pathol 6: 115-124

Kaelin Jr WG (2002) Molecular basis of the VHL hereditary cancer syndrome. Nat Rev Cancer 2: 673-682

Katoh R (2003) Angiogenesis in endocrine glands: special reference to the expression of vascular endothelial growth factor. Microsc Res Tech 60: $181-185$

La Rosa S, Uccella S, Finzi G, Albarello L, Sessa F, Capella C (2003) Localization of vascular endothelial growth factor and its receptors in digestive endocrine tumors: correlation with microvessel density and clinicopathologic features. Hum Pathol 34: 18-27

LeCouter J, Kowalski J, Foster J, Hass P, Zhang Z, Dillard-Telm L, Frantz G, Rangell L, DeGuzman L, Keller GA, Peale F, Gurney A, Hillan KJ, Ferrara $\mathrm{N}$ (2001) Identification of an angiogenic mitogen selective for endocrine gland endothelium. Nature 412: $877-884$

Loncaster JA, Harris AL, Davidson SE, Logue JP, Hunter RD, Wycoff CC, Pastorek J, Ratcliffe PJ, Stratford IJ, West CM (2001) Carbonic anhydrase (CA IX) expression, a potential new intrinsic marker of hypoxia: correlations with tumor oxygen measurements and prognosis in locally advanced carcinoma of the cervix. Cancer Res 61: 6394-6399

Madeira I, Terris B, Voss M, Denys A, Sauvanet A, Flejou JF, Vilgrain V, Belghiti J, Bernades P, Ruszniewski P (1998) Prognostic factors in patients with endocrine tumours of the duodenopancreatic area. Gut 43: $422-427$

Maeda K, Chung YS, Takatsuka S, Ogawa Y, Onoda N, Sawada T, Kato Y, Nitta A, Arimoto Y, Kondo Y (1995) Tumour angiogenesis and tumour cell proliferation as prognostic indicators in gastric carcinoma. $\mathrm{Br} J$ Cancer 72: $319-323$ 
Marion-Audibert AM, Barel C, Gouysse G, Dumortier J, Pilleul F, Pourreyron C, Hervieu V, Poncet G, Lombard-Bohas C, Chayvialle JA, Partensky C, Scoazec JY (2003) Low microvessel density is an unfavorable histoprognostic factor in pancreatic endocrine tumors. Gastroenterology 125: $1094-1104$

Maxwell PH, Ratcliffe PJ (2002) Oxygen sensors and angiogenesis. Semin Cell Dev Biol 13: 29-37

Moore PS, Missiaglia E, Antonello D, Zamo A, Zamboni G, Corleto V, Falconi M, Scarpa A (2001) Role of disease-causing genes in sporadic pancreatic endocrine tumors: MEN1 and VHL. Genes Chromosomes Cancer 32: $177-181$

Niedergethmann M, Hildenbrand R, Wostbrock B, Hartel M, Sturm JW, Richter A, Post S (2002) High expression of vascular endothelial growth factor predicts early recurrence and poor prognosis after curative resection for ductal adenocarcinoma of the pancreas. Pancreas 25: $122-129$

Opavsky R, Pastorekova S, Zelnik V, Gibadulinova A, Stanbridge EJ, Zavada J, Kettmann R, Pastorek J (1996) Human MN/CA9 gene, a novel member of the carbonic anhydrase family: structure and exon to protein domain relationships. Genomics 33: $480-487$

Pastorekova S, Zavadova Z, Kostal M, Babusikova O, Zavada J (1992) A novel quasi-viral agent, $\mathrm{MaTu}$, is a two-component system. Virology 187: 620-626

Pezzella F, Pastorino U, Tagliabue E, Andreola S, Sozzi G, Gasparini G, Menard S, Gatter KC, Harris AL, Fox S, Buyse M, Pilotti S, Pierotti M, Rilke F (1997) Non-small-cell lung carcinoma tumor growth without morphological evidence of neo-angiogenesis. Am J Pathol 151: $1417-1423$

Prall F, Gringmuth U, Nizze H, Barten M (2003) Microvessel densities and microvascular architecture in colorectal carcinomas and their liver metastases: significant correlation of high microvessel densities with better survival. Histopathology 42: 482-491

Pugh CW, Ratcliffe PJ (2003) Regulation of angiogenesis by hypoxia: role of the HIF system. Nat Med 9: 677-684

Ryschich E, Schmidt J, Hammerling GJ, Klar E, Ganss R (2002) Transformation of the microvascular system during multistage tumorigenesis. Int J Cancer 97: 719-725

Sasano H, Ohashi Y, Suzuki T, Nagura H (1998) Vascularity in human adrenal cortex. Mod Pathol 11: 329-333

Semenza GL (2001) HIF-1 and mechanisms of hypoxia sensing. Curr Opin Cell Biol 13: $167-171$

Seo Y, Baba H, Fukuda T, Takashima M, Sugimachi K (2000) High expression of vascular endothelial growth factor is associated with liver metastasis and a poor prognosis for patients with ductal pancreatic adenocarcinoma. Cancer 88: 2239-2245

Solcia E, Klöppel G, Sobin L (2000) Histological Typing of Endocrine Tumours, 2nd edn. New York: Springer-Verlag
Talks KL, Turley H, Gatter KC, Maxwell PH, Pugh CW, Ratcliffe PJ, Harris AL (2000) The expression and distribution of the hypoxia-inducible factors HIF-1alpha and HIF-2alpha in normal human tissues, cancers, and tumor-associated macrophages. Am J Pathol 157: 411-421

Terris B, Scoazec JY, Rubbia L, Bregeaud L, Pepper MS, Ruszniewski P, Belghiti J, Flejou J, Degott C (1998) Expression of vascular endothelial growth factor in digestive neuroendocrine tumours. Histopathology 32: $133-138$

Turley H, Scott PA, Watts VM, Bicknell R, Harris AL, Gatter KC (1998) Expression of VEGF in routinely fixed material using a new monoclonal antibody VG1. J Pathol 186: 313-318

Turner HE, Nagy Z, Gatter KC, Esiri MM, Harris AL, Wass JA (2000a) Angiogenesis in pituitary adenomas - relationship to endocrine function, treatment and outcome. J Endocrinol 165: 475-481

Turner HE, Nagy Z, Gatter KC, Esiri MM, Harris AL, Wass JA (2000b) Angiogenesis in pituitary adenomas and the normal pituitary gland. I Clin Endocrinol Metab 85: 1159-1162

Turner HE, Nagy Z, Gatter KC, Esiri MM, Wass JA, Harris AL (2000c) Proliferation, bcl-2 expression and angiogenesis in pituitary adenomas: relationship to tumour behaviour. $\mathrm{Br}$ J Cancer 82: 1441 - 1445

Turner KJ, Crew JP, Wykoff CC, Watson PH, Poulsom R, Pastorek J, Ratcliffe PJ, Cranston D, Harris AL (2002) The hypoxia-inducible genes VEGF and CA9 are differentially regulated in superficial vs invasive bladder cancer. $\mathrm{Br}$ J Cancer 86: 1276 - 1282

Weidner N (1995) Intratumor microvessel density as a prognostic factor in cancer. Am J Pathol 147: 9-19

Weidner N (1998) Tumoural vascularity as a prognostic factor in cancer patients: the evidence continues to grow. J Pathol 184: 119-122

Weidner N, Folkman J, Pozza F, Bevilacqua P, Allred EN, Moore DH, Meli S, Gasparini G (1992) Tumor angiogenesis: a new significant and independent prognostic indicator in early-stage breast carcinoma. $J$ Natl Cancer Inst 84: 1875 - 1887

Wykoff CC, Beasley NJ, Watson PH, Turner KJ, Pastorek J, Sibtain A, Wilson GD, Turley H, Talks KL, Maxwell PH, Pugh CW, Ratcliffe PJ, Harris AL (2000) Hypoxia-inducible expression of tumor-associated carbonic anhydrases. Cancer Res 60: 7075-7083

Wykoff CC, Pugh CW, Harris AL, Maxwell PH, Ratcliffe PJ (2001) The HIF pathway: implications for patterns of gene expression in cancer. Novartis Found Symp 240: 212-225, discussion 225-231

Zagzag D, Zhong H, Scalzitti JM, Laughner E, Simons JW, Semenza GL (2000) Expression of hypoxia-inducible factor lalpha in brain tumors: association with angiogenesis, invasion, and progression. Cancer 88: $2606-2618$

Zhong H, De Marzo AM, Laughner E, Lim M, Hilton DA, Zagzag D, Buechler P, Isaacs WB, Semenza GL, Simons JW (1999) Overexpression of hypoxia-inducible factor 1alpha in common human cancers and their metastases. Cancer Res 59: 5830-5835 